$\underline{\text { Review Article }}$

\title{
Antifungal Susceptibility Testing: Current Role from the Clinical Laboratory Perspective
}

\author{
Brunella Posteraro ${ }^{1}$, Riccardo Torelli ${ }^{2}$, Elena De Carolis ${ }^{2}$, Patrizia Posteraro ${ }^{3}$ and Maurizio Sanguinetti ${ }^{2}$ \\ ${ }^{1}$ Institute of Public Health (Section of Hygiene), Università Cattolica del Sacro Cuore, Largo F. Vito, 1-00168, \\ Rome, Italy. \\ ${ }^{2}$ Institute of Microbiology, Università Cattolica del Sacro Cuore, Largo F. Vito, 1-00168, Rome, Italy. \\ ${ }^{3}$ Clinical Laboratory, Ospedale San Carlo, Via Aurelia, 275-00165, Rome, Italy.
}

Correspondence to: Maurizio Sanguinetti, Institute of Microbiology, Università Cattolica del Sacro Cuore, Largo F. Vito, 1-00168, Rome, Italy. Tel: +39-06-3015-4964. Fax: +39-06-3051-152. E-mail: msanguinetti@rm.unicatt.it

Competing interests: The authors have declared that no competing interests exist.

Published: April 7, 2014

Received: February 9, 2014

Accepted: March 19, 2014

Citation: Mediterr J Hematol Infect Dis 2014, 6(1): e2014030, DOI: 10.4084/MJHID.2014.030

This article is available from: http://www.mjhid.org/article/view/12938

This is an Open Access article distributed under the terms of the Creative Commons Attribution License (http://creativecommons.org/licenses/by/2.0), which permits unrestricted use, distribution, and reproduction in any medium, provided the original work is properly cited.

Abstract. Despite availability of many antifungal agents, antifungal clinical resistance occurs, perhaps as a consequence of an infecting organism found to be resistant in vitro to one or more antifungals tested. From what derives the important current role of the in vitro antifungal susceptibility testing (AFST), that is to determine which agents are like to be scarcely effective for a given infection. Thus, AFST results, if timely generated by the clinical microbiology laboratory and communicated to clinicians, can aid them in the therapeutic decision making, especially for difficult-to-treat invasive candidiasis and aspergillosis. Although recently refined AFST methods are commercially available for allowing a close antifungal resistance surveillance in many clinical setting, novel assays such as flow cytometry or MALDI-TOF mass spectrometry are upcoming tools for AFST. Based on short-time antifungal drug exposure of fungal isolates, these assays could provide a reliable means for quicker and sensitive assessment of AFST.

Introduction. Although several factors are key determinants of antifungal clinical resistance, ${ }^{1}$ which is referred to as the persistence or progression of a fungal infection despite the administration of appropriate antifungal therapy, there is a general consensus that clinical outcomes are better when treatments are started early. ${ }^{2,3}$ Almost all the classes of systemically active antifungal agents available to date, such as polyenes (i.e., amphotericin B), azoles, flucytosine, and the newest echinocandins contribute to improve the management of invasive fungal infections (IFIs). ${ }^{4-6}$
Nevertheless, the rate of antifungal failures is high, and the emergence of resistant fungal strains is a growing concern, particularly for strains capable of exhibiting resistance to commonly prescribed antifungal drugs. ${ }^{7}$ Eighteen (11.1\%) of 162 fluconazole-resistant bloodstream isolates of Candida glabrata collected during two large surveillance programs were found to be cross-resistant to one or more of the echinocandins. ${ }^{8}$ Likewise, patients with chronic pulmonary Aspergillus infection who receive prolonged (tri)azole therapy are at risk of resistant aspergillosis, ${ }^{9}$ with an evolving 
spectrum of resistance owing to the emergence of noncyp51A-mediated mechanisms, ${ }^{10}$ as well as are at risk azole-naïve patients due to the presence of resistant TR/L98H strains (i.e., carrying a substitution at codon 98 in the cyp51A gene in combination with a 34 basepair tandem repeat in the gene promoter) in the environment. ${ }^{11,12}$ Thus, while two-thirds of surveyed Dutch patients with azole-resistant Aspergillus disease had not history of previous azole exposure (with all $A$. fumigatus isolates from patients with invasive aspergillosis harboring the TR/L98H mutation), ${ }^{13}$ recent epidemiological data show that this resistance mechanism, first emerged in the Netherlands, is expanding not only in European countries but also in China, Iran, and India. ${ }^{10}$

Antifungal Susceptibility Testing to Aid the Management of IFI Patients. The primary utility of antifungal susceptibility testing (AFST) arises from the concept that susceptibility (or resistance) to an antifungal agent selected for the therapy would allow some prediction about the impact that administration of the agent tested in vitro has on the clinical outcome of infection caused by the treated organism. ${ }^{14,15}$ Therefore, clinical microbiologists are currently engaged to determine the growth of fungi under different drug concentrations so as to yield the minimum inhibitory concentration (MIC) for a specific infecting isolate, that is an in vitro measure of susceptibility (expressed as growth inhibition) which helps to predict the therapeutic efficacy. ${ }^{16}$ Thus, it is important that MIC results are timely communicated to physicians to guide them in the therapeutic decision making, in the same way that antibacterial testing aids in the clinical guidance of bacterial infections. ${ }^{17}$

As attested by several studies evaluating the role of "real-time" AFST in managing patients with invasive Candida infections, ${ }^{18}$ physicians frequently (and appropriately) adjust the therapy on the basis of MIC results, although a clearly defined association between the timely receipt of antifungal therapy and poor outcome after Candida bloodstream infection due to a resistant isolate is lacking to date. ${ }^{2}$ Indeed, Collins et al. ${ }^{19}$ reported that the susceptibility testing (especially when done in-house) of $C$. glabrata isolates may facilitate quicker interventions (i.e., de-escalation of therapy from an expensive echinocandin to fluconazole) for patients with documented C. glabrata fungemia, thereby resulting in lower overall treatment costs. Likewise, Grim et al. $^{20}$ found that receipt of appropriate early antifungal therapy (i.e., administered within $72 \mathrm{~h}$ of a positive culture being drawn) was associated with a significant $(P=0.047)$ survival benefit for patients who were effectively treated for $\geq 24 \mathrm{~h}$, and their results were supported by the inclusion of routine AFST to optimally assess the adequateness of therapy.

Unlike Candida infection, there is only a limited number of reported Aspergillus infection cases that could elucidate the clinical impact of azole resistance on the patient's outcome, ${ }^{21}$ and this situation has hindered the wide application of in vitro AFST of Aspergillus species. However, in an attempt to establish clinically derived breakpoints for Aspergilli that would help physicians to interpret the MIC values as produced from the clinical microbiology laboratory, a pragmatic (and not formal) approach was followed by Verweij et al. $^{21}$ Thus, taking MIC distribution, pharmacokinetic/pharmacodynamic parameters of antifungal azoles, in vivo experimental correlation between cyp51A point mutations and failure, and clinical experience into account, interpretive breakpoints were proposed, that is MICs $>2 \mu \mathrm{g} / \mathrm{ml}$ for itraconazole and voriconazole and $>0.5 \mu \mathrm{g} / \mathrm{ml}$ for posaconazole. ${ }^{21}$ These breakpoints were able to discriminate between wild-type (that refers to isolates without mutational or acquired mechanisms of resistance) and non-wild-type (that refers to isolates with mutational or acquired mechanisms of resistance) MIC distributions for itraconazole and voriconazole among 325 consecutive clinical $A$. fumigatus isolates from the Nijmegen fungus culture collection. ${ }^{21}$ Based on these findings, a 4-well azole-agar dilution (4D) plate (i.e., 3 wells were each containing one of azoles: itraconazole $4 \mu \mathrm{g} / \mathrm{ml}$, voriconazole $1 \mu \mathrm{g} / \mathrm{ml}$, or posaconazole $0.5 \mu \mathrm{g} / \mathrm{ml}$; and the fourth azole-free well served as control growth) was developed as a screening test for identifying potentially resistant $A$. fumigatus isolates. ${ }^{22}$ In parallel, Pfaller et al. ${ }^{23}$ used a collection of 637 geographically diverse, clinical isolates of $A$. fumigatus tested against itraconazole, posaconazole, and voriconazole, to assess the wild-type MIC distribution and epidemiological cutoff values (ECVs), that is MIC threshold values for differentiating wildtype isolates from non-wild-type isolates, for $A$. fumigatus and the mold-active triazoles.

By contrast, due to scarce (and less frequent than for azoles) tendency to carrying out AFST for Aspergillus isolates, ${ }^{24}$ perhaps as a result of technical difficulties and suboptimal reproducibility of the methods employed, ${ }^{25}$ echinocandin resistance in Aspergillus species is much less known. ${ }^{22}$ Although the caspofungin is recommended as a second line treatment choice for invasive aspergillosis ${ }^{26}$, and often administered in combination with amphotericin $\mathrm{B}^{21}$, however, breakthrough infections (though sporadic) have been reported in patients under caspofungin therapy, ${ }^{27-29}$, and they involved A. fumigatus isolates, with elevated minimum effective concentrations (MECs) to caspofungin. The MEC endpoint, defined as 
the lowest drug concentration that leads to the growth of small, rounded, compact hyphal forms as compared to the hyphal growth seen in the growth control well, was suggested for testing antifungal susceptibility of Aspergilli to echinocandins, rather than the MIC; ${ }^{25}$ nonetheless, MEC remains technically difficult to determine.

Antifungal Susceptibility Testing in the Daily Laboratory Practice. Several recommendations for routine use of AFST of Candida species in the clinical microbiology laboratory have been developed. ${ }^{18}$ They include testing of fluconazole and an echinocandin against C. glabrata isolated from deep sites and, possibly, against other species of Candida, unless their antifungal susceptibility pattern is predictable (i.e., for Candida krusei); use of clinical breakpoints (CBPs) or ECVs to interpret MIC values as appropriate; considering cross-resistance between fluconazole and all other triazoles (itraconazole, posaconazole, and voriconazole) to be complete for C. glabrata; and careful choice of susceptibility testing methods. ${ }^{18}$ In essence, a selective application of AFST, together with a precise identification of Candida to the species level, ${ }^{30}$ should be useful in selecting agents for primary therapy as well as in a de-escalating strategy, ${ }^{18}$ especially in difficult-to-manage cases of invasive candidiasis. $^{31}$

With regards to Aspergillus species, it is currently recommended to perform AFST of clinically relevant Aspergilli (with isolates at least identified to the species level) ${ }^{32}$ as an adjunct to the treatment for IFI patients when therapeutic failure of initial therapy or breakthrough infection occur, and for patients with disease and long-term triazole treatment and/or recurrent isolation of an Aspergillus species. ${ }^{25}$ Also, whereas isolates of Aspergillus species known to be intrinsically drug-resistant (e.g., A. terreus against amphotericin B) need to be not usually tested, ${ }^{25}$ MIC determination could be useful to monitor the emergence of polyene resistance in Aspergillus species such as $A$. flavus. ${ }^{33}$

Conventional and Novel Laboratory Assays for Testing Antifungal Susceptibility. Standardized microdilution-based procedures by the Clinical and Laboratory Standards Institute (CLSI) and the European Committee on Antibiotic Susceptibility Testing (EUCAST), ${ }^{34-38}$ are universally accepted for performing AFST (Table 1), but these procedures are complex, time-consuming, and not intended for routine use. ${ }^{39}$ As a result of a multistep process based on the analysis of MIC distribution curves for wild-type populations and the clinical relationship between MIC values and efficacy, ${ }^{40,41}$ CLSI/EUCAST MIC breakpoints (i.e., obtained with CLSI/EUCAST reference methods in specialized mycology laboratories) are to date available to interpret the AFST results of amphotericin $\mathrm{B}$, azoles, and echinocandins for Candida, and amphotericin B and azoles for Aspergillus. ${ }^{42}$ Besides to be an important step in establishing fungal CBPs, the MIC distributions of wild-type fungal populations provide a measure of the ECVs, which, in the absence of specific CBPs, may be very useful in antifungal resistance surveillance to monitor the emergence of resistant isolates (i.e., those with gene mutations associated with reduced therapeutic responses). ${ }^{7}$ Also, AFST using the CLSI/EUCAST reference methods is a precious tool for studying the in vitro activity of new and experimental compounds, as well as the epidemiology of antifungal-resistant fungi. Finally, through recently refined AFST methods, ${ }^{24}$ coupled with detection of molecular fungal alterations conferring reduced antifungal drug susceptibility, ${ }^{43}$ often directly from clinical specimens, ${ }^{44,45}$ it is now possible to ensure a close antifungal resistance surveillance in many clinical settings. The detection of cyp51A gene mutations in primary clinical specimens is still the sole strategy for detecting Aspergillus resistance to triazoles in the absence of culture confirmation, which occurs in most cases of invasive and chronic pulmonary aspergillosis, making an MIC determination impossible. ${ }^{21,22}$ However, these nucleic acid-based assays, though permitting quicker detection of azoleresistance in culture positive samples, are to date not standardized or practical for most clinical laboratories, ${ }^{42}$ in addition to be unable to reveal the influence from other resistance mechanisms. ${ }^{21,22}$ Given these concerns and the aforementioned increasing number of resistance cases, performing susceptibility testing of Aspergillus isolates before and during antifungal treatment can be clinically relevant. ${ }^{22}$ Yet, since obtaining repeated Aspergillus positive cultures from patients receiving antifungal therapy (that would allow to prove that a treatment failure is actually due to an antifungal-resistant organism) is an uncommon clinical scenario, monitoring of the galactomannan (GM) biomarker through serial GM index measurements following antifungal treatment ${ }^{46,47}$ could be effective for detecting resistance to antifungal therapy.

Commercially available tests, such as Sensititre YeastOne, Etest, and the fully automated Vitek 2 yeast susceptibility system (Table 1), all easy-to-use modifications from the CLSI/EUCAST reference methods are widely used for testing antifungal susceptibility of relevant Candida and Aspergillus species. ${ }^{7}$ While the commercial tests show a good essential agreement (defined as MICs within 2 
Table 1. Reference and non-reference methods for antifungal susceptibility testing of Candida and Aspergillus clinical isolates ${ }^{\mathrm{a}}$

\begin{tabular}{|c|c|c|c|c|c|c|c|c|c|}
\hline \multirow[t]{2}{*}{ Characteristic } & \multicolumn{2}{|c|}{ Standardized Methods } & \multicolumn{3}{|c|}{ Commercial Methods } & \multicolumn{4}{|c|}{ Novel Methods } \\
\hline & CLSI & EUCAST & SYO & Etest & Vitek 2 & FC & MALDI-TOF MS & IMC & $4 \mathrm{D}$ plate \\
\hline Suitability & $\begin{array}{l}\text { Yeasts (M27-A3), molds } \\
\text { (M38-A2) }\end{array}$ & $\begin{array}{l}\text { Fermentative yeasts } \\
\text { (EDef.7.2), molds } \\
\text { (EDef.9.1) }\end{array}$ & Yeasts and molds & Yeasts and molds & Yeasts & Candida species & Candida albicans & $\begin{array}{l}\text { Aspergillus } \\
\text { species }\end{array}$ & $\begin{array}{l}\text { Aspergillus } \\
\text { species }\end{array}$ \\
\hline Format $^{\mathrm{b}}$ & BMD & BMD & BMD & $\begin{array}{l}\text { Agar-based } \\
\text { method }\end{array}$ & $\begin{array}{l}\text { BMD (AST-YS06 } \\
\text { cards) }\end{array}$ & Broth dilution & Broth dilution & Broth dilution & Agar dilution \\
\hline Temperature & $35^{\circ} \mathrm{C}$ & $35-37^{\circ} \mathrm{C}$ & $35-37^{\circ} \mathrm{C}$ & $35-37^{\circ} \mathrm{C}$ & $\begin{array}{l}\text { Instrument } \\
\text { incubator }\end{array}$ & $35^{\circ} \mathrm{C}$ & $37^{\circ} \mathrm{C}$ & $37^{\circ} \mathrm{C}$ & $37^{\circ} \mathrm{C}$ \\
\hline Incubation time & $24-48 \mathrm{~h}$ & $24-48 \mathrm{~h}$ & $24-48 \mathrm{~h}$ & $24-48 \mathrm{~h}$ & $12-24 \mathrm{~h}$ & $1-4 \mathrm{~h}$ & $3 \mathrm{~h}$ & $48 \mathrm{~h}$ & $48 \mathrm{~h}$ \\
\hline Reading & Visually & $\begin{array}{l}\text { Visually/spectrophotome } \\
\text { trically }\end{array}$ & Visually & & Automatically & $\begin{array}{l}\text { Fluorescence } \\
\text { microscopy }\end{array}$ & Mass spectrometry & $\begin{array}{l}\text { Isothermal } \\
\text { microcalorimeter }\end{array}$ & Visually \\
\hline Endpoint $^{\mathrm{C}}$ & $\begin{array}{l}\text { MIC, MEC (only for } \\
\text { echinocandins) }\end{array}$ & MIC & $\begin{array}{l}\text { MIC, MEC (only for } \\
\text { echinocandins) }\end{array}$ & MIC & MIC & MFEC & $\begin{array}{l}\text { CCI-measured } \\
\text { spectral comparison }\end{array}$ & MHIC & No growth \\
\hline $\begin{array}{l}\text { Use (pros and } \\
\text { cons) }{ }^{\mathrm{d}}\end{array}$ & $\begin{array}{l}\text { Detecting resistant } \\
\text { isolates, but restricted to } \\
\text { specialized laboratories }\end{array}$ & $\begin{array}{l}\text { Detecting resistant } \\
\text { isolates, but restricted to } \\
\text { specialized laboratories }\end{array}$ & $\begin{array}{l}\text { Routine testing of } \\
\text { isolates, but } \\
\text { categorization of } \\
\text { resistant isolates not } \\
\text { advised }\end{array}$ & $\begin{array}{l}\text { Routine testing of } \\
\text { isolates, but } \\
\text { categorization of } \\
\text { resistant isolates } \\
\text { not advised }\end{array}$ & $\begin{array}{l}\text { Routine testing of } \\
\text { isolates, but } \\
\text { categorization of } \\
\text { resistant isolates } \\
\text { not advised }\end{array}$ & $\begin{array}{l}\text { Rapid detection of } \\
\text { antifungal } \\
\text { resistance, but } \\
\text { today not applied } \\
\text { to the routine } \\
\text { clinical practice }\end{array}$ & $\begin{array}{l}\text { Rapid detection of } \\
\text { caspofungin } \\
\text { resistance, but } \\
\text { today not applied to } \\
\text { the routine clinical } \\
\text { practice }\end{array}$ & $\begin{array}{l}\text { Potential } \\
\text { detection of } \\
\text { resistant isolates, } \\
\text { but still in an } \\
\text { infancy stage }\end{array}$ & $\begin{array}{l}\text { Screening for } \\
\text { potentially azole- } \\
\text { resistant isolates, } \\
\text { but confirmation } \\
\text { by the reference } \\
\text { method required }\end{array}$ \\
\hline
\end{tabular}

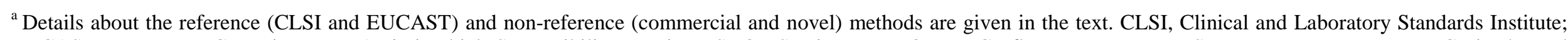
EUCAST, European Committee on Antimicrobial Susceptibility Testing; SYO, Sentitre Yeastㅁne; FC, flow cytometry; MS, mass spectrometry; IMC, isothermal microcalorimetry; 4D; $\underline{4}$-well azole-agar dilution.

${ }^{\mathrm{b}}$ The indicated commercial methods actually represent modifications of standardized agar or broth microdilution (BMD) methods.

${ }^{\mathrm{c}}$ The indicated endpoints include MFEC (minimum fluorescence-enhancing concentration) and MHIC (minimal heat inhibitory concentration) for the FC and IMC methods, respectively; for MALDI-TOF MS, the endpoint represents a composite correlation index (CCI) value as obtained after the CCI values, derived by matching fungal spectra at

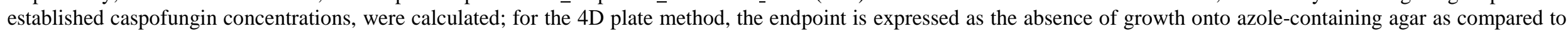
the free-azole growth control well. These endpoints are alternatives to the traditional MIC (minimum inhibitory concentration) and MEC (minimum effective concentration) used with conventional methods, as indicated.

${ }^{\mathrm{d}}$ According to expert recommendations on the use of each method in the clinical microbiology laboratory, as specified in the text. 
dilutions) with the reference methods, the categorical agreement (i.e., agreement in the categorization of an isolate as susceptible, intermediate, or resistant) may be lower, especially for the echinocandin class of antifungal agents. ${ }^{48-50}$ Thus, it was noted that clinical fungal isolates should not be classified as resistant in vitro by commercial methods, unless standardization processes and setting of their own breakpoints have been undertaken. ${ }^{39}$ As MIC determination by reference methods is highly recommended for patient management, ${ }^{51}$ periodical epidemiological surveys of deep, blood, and mucosal infections should be done to monitor antifungal susceptibilities of Candida and Aspergillus. So, local surveillance MIC data, derived from a routine microbiology laboratory workflow, can be used to develop treatment strategies, particularly by clinicians who prescribe preemptively or empirically antifungals in hematology, transplantation, or intensive care units. In parallel, antifungal resistance surveillance studies should also investigate air samples for the presence of $A$. fumigatus resistant to medical triazoles in the hospital environment to ascertain the local resistance risk among filamentous fungi. Therefore, both clinical and environmental samples can be screened using the aforementioned 4D plates ${ }^{52}$ to evaluate to what extent exposure to azoles in patients ${ }^{9}$ or in the environment ${ }^{11}$ contributes to antifungal resistance in the hospital setting.

New diagnostic approaches, based on emerging technologies such as flow cytometry (FC), MALDITOF mass spectrometry (MALDI-TOF MS), and isothermal microcalorimetry (IMC) (Table 1), have been developed to expand, and potentially improve, the capability of the clinical microbiology laboratory to yield AFST results. By flow cytometry (FC), the effects of a given antifungal drug can be appreciated by observing alterations in the fungal cell viability (rather than the growth inhibition as in conventional methods) that will be identified via changes in the measured cell fluorescence; ${ }^{53}$ this led to assess the minimum fluorescence-enhancing concentration (MFEC), that is the lowest concentration of antifungal agent to which the percentage of cells showing altered fluorescence is superior to a predetermined cutoff value (set at $50 \%$ for C. glabrata and C. krusei, and at $40 \%$ for Candida parapsilosis). ${ }^{54}$ Using MALDI-TOF MS, a simple and rapid AFST assay (named ms-AFST) was established to discriminate susceptible and resistant isolates of
Candida albicans after a 3-h incubation in the presence of "breakpoint" concentrations of caspofungin; after the fungal spectra at concentration $0,0.03$, or $32 \mu \mathrm{g} / \mathrm{ml}$ of caspofungin were compared to create individual composite correlation index (CCI) matrices, the tested isolates were classified as susceptible or resistant to caspofungin if the CCI values of the spectra at 0.03 and $32 \mu \mathrm{g} / \mathrm{ml}$ were, respectively, higher or lower than the CCI values of the spectra at 0.03 and $0 \mu \mathrm{g} / \mathrm{ml} .^{55}$ Finally, IMC was evaluated for "real-time" susceptibility testing of Aspergillus species, by measuring the thermal variations induced by the action of antifungals; this led to define the minimal heat inhibitory concentration (MHIC), that is the lowest antifungal concentration which inhibits $50 \%$ of the total heat produced by the growth control at $48 \mathrm{~h}$ or, only for anidulafungin and caspofungin, the lowest antifungal concentration which reduces the heat-flow peak by $50 \%{ }^{56}$ It should be noted that while the timeto-result of an IMC assay is surely not different from that of conventional MIC methods (Table 1), the susceptibility endpoints for the echinocandins are hard to determine due to significant trailing growth, and the MEC reading is actually subjective and poorly reproducible. $^{22}$ As an alternative to the classical MIC, the new endpoints could then provide a simple, reliable, and accurate means of identifying antifungalresistant isolates, thus potentiating the practicability and the clinical utility of AFST. However, further studies need to be undertaken to improve reproducibility and standardization of the recent developments in AFST, in order to transform them in clinical useful assays in the next future.

Conclusions. Although AFST is considered currently a valid method, it remains a very dynamic field of clinical microbiology, as further research is needed before MICs are independently used to guide treatment decisions ${ }^{15}$ and before the standardization process is completed to include all known antifungal compounds and fungal species ${ }^{42}$. While a crucial issue is whether current AFST methods and antifungal breakpoints are capable of identifying resistant fungal isolates, associated with treatment failures, new alternate AFST methods should be introduced to improve the detection of antifungal resistance, which is perhaps the most challenging goal in clinical microbiology.

\section{References:}

1. Kanafani ZA, Perfect JR. Antimicrobial resistance: resistance to antifungal agents: mechanisms and clinical impact. Clin Infect Dis. 2008; 46:120-128. http://dx.doi.org/10.1086/524071

2. Karthaus M, Rüping MJ, Cornely OA, Steinbach A, Groll AH, Lass-Flörl C, Ostermann H, Ruhnke M, Vehreschild JJ. Current issues in the clinical management of invasive Candida infections--

the AGIHO, DMykG, ÖGMM and PEG web-based survey and expert consensus conference 2009. Mycoses. 2011; 54:e546-e556. http://dx.doi.org/10.1111/j.1439-0507.2010.01988.x

3. Walsh TJ, Gamaletsou MN. Treatment of fungal disease in the setting of neutropenia. Hematology Am Soc Hematol Educ Program. 2013; 2013:423-427. 
http://dx.doi.org/10.1182/asheducation-2013.1.423

4. Cordonnier C, Pautas C, Maury S, Vekhoff A, Farhat H, Suarez F, Dhédin N, Isnard F, Ades L, Kuhnowski F, Foulet F, Kuentz M, Maison P, Bretagne S, Schwarzinger M. Empirical versus preemptive antifungal therapy for high-risk, febrile, neutropenic patients: a randomized, controlled trial. Clin Infect Dis. 2009; 48:1042-1051. http://dx.doi.org/10.1086/597395

5. Cornely OA, Aversa F, Cook P, Jones B, Michallet M, Shea T, Vallejo C. Evaluating the role of prophylaxis in the management of invasive fungal infections in patients with hematologic malignancy. Eur J Haematol. 2011; 87:289-301. http://dx.doi.org/10.1111/j.1600-0609.2011.01682.x

6. Maertens J, Marchetti O, Herbrecht R, Cornely OA, Flückiger U, Frêre P, Gachot B, Heinz WJ, Lass-Flörl C, Ribaud P, Thiebaut A, Cordonnier C; Third European Conference on Infections in Leukemia. European guidelines for antifungal management in leukemia and hematopoietic stem cell transplant recipients: summary of the ECIL 3--2009 update. Bone Marrow Transplant. 2011; 46:709-718. http://dx.doi.org/10.1038/bmt.2010.175

7. Pfaller MA. Antifungal drug resistance: mechanisms, epidemiology, and consequences for treatment. Am J Med. 2012; 125:S3-S13. http://dx.doi.org/10.1016/j.amjmed.2011.11.001

8. Pfaller MA, Castanheira M, Lockhart SR, Ahlquist AM, Messer SA, Jones RN. Frequency of decreased susceptibility and resistance to echinocandins among fluconazole-resistant bloodstream isolates of Candida glabrata. J Clin Microbiol. 2012; 50:1199-1203. http://dx.doi.org/10.1128/JCM.06112-11

9. Howard SJ, Cerar D, Anderson MJ, Albarrag A, Fisher MC, Pasqualotto AC, Laverdiere M, Arendrup MC, Perlin DS, Denning DW. Frequency and evolution of azole resistance in Aspergillus fumigatus associated with treatment failure. Emerg Infect Dis. 2009; 15:1068-1076. http://dx.doi.org/10.3201/eid1507.090043

10. Vermeulen E, Lagrou K, Verweij PE. Azole resistance in Aspergillus fumigatus: a growing public health concern. Curr Opin Infect Dis. 2013; 26:493-500. http://dx.doi.org/10.1097/QCO.0000000000000005

11. Snelders E, van der Lee HA, Kuijpers J, Rijs AJ, Varga J, Samson RA, Mellado E, Donders AR, Melchers WJ, Verweij PE. Emergence of azole resistance in Aspergillus fumigatus and spread of a single resistance mechanism. PLoS Med. 2008; 5:e219. http://dx.doi.org/10.1371/journal.pmed.0050219

12. Verweij PE, Snelders E, Kema GH, Mellado E, Melchers WJ. Azole resistance in Aspergillus fumigatus: a side-effect of environmental fungicide use? Lancet Infect Dis. 2009; 9:789-795. http://dx.doi.org/10.1016/S1473-3099(09)70265-8

13. van der Linden JW, Snelders E, Kampinga GA, Rijnders BJ, Mattsson E, Debets-Ossenkopp YJ, Kuijper EJ, Van Tiel FH, Melchers WJ, Verweij PE. Clinical implications of azole resistance in Aspergillus fumigatus, The Netherlands, 2007-2009. Emerg Infect Dis. 2011; 17:1846-1854. http://dx.doi.org/10.3201/eid1710.110226

14. Rex JH, Pfaller MA. Has antifungal susceptibility testing come of age? Clin Infect Dis. 2002; 35:982-989. http://dx.doi.org/10.1086/342384

15. Eschenauer GA, Carver PL. The evolving role of antifungal susceptibility testing. Pharmacotherapy. 2013; 33:465-475. http://dx.doi.org/10.1002/phar.1233

16. Arikan S. Current status of antifungal susceptibility testing methods. Med Mycol. 2007; 45:569-587. http://dx.doi.org/10.1080/13693780701436794

17. Turnidge J, Paterson DL. Setting and revising antibacterial susceptibility breakpoints. Clin Microbiol Rev. 2007; 20:391-408. http://dx.doi.org/10.1128/CMR.00047-06

18. Pfaller MA, Diekema DJ. Progress in antifungal susceptibility testing of Candida spp. by use of Clinical and Laboratory Standards Institute broth microdilution methods, 2010 to 2012. J Clin Microbiol. 2012; 50:2846-2856. http://dx.doi.org/10.1128/JCM.00937-12

19. Collins CD, Eschenauer GA, Salo SL, Newton DW. To test or not to test: a cost minimization analysis of susceptibility testing for patients with documented Candida glabrata fungemias. J Clin Microbiol. 2007; 45:1884-1888. http://dx.doi.org/10.1128/JCM.00192-07

20. Grim SA, Berger K, Teng C, Gupta S, Layden JE, Janda WM, Clark NM. Timing of susceptibility-based antifungal drug administration in patients with Candida bloodstream infection: correlation with outcomes. J Antimicrob Chemother. 2012; 67:707714. http://dx.doi.org/10.1093/jac/dkr511

21. Verweij PE, Howard SJ, Melchers WJ, Denning DW. Azoleresistance in Aspergillus: proposed nomenclature and breakpoints. Drug Resist Updat. 2009; 12:141-147. http://dx.doi.org/10.1016/j.drup.2009.09.002

22. Howard SJ, Arendrup MC. Acquired antifungal drug resistance in Aspergillus fumigatus: epidemiology and detection. Med Mycol. 2011; 49:S90-S95. http://dx.doi.org/10.3109/13693786.2010.508469

23. Pfaller MA, Diekema DJ, Ghannoum MA, Rex JH, Alexander BD, Andes D, Brown SD, Chaturvedi V, Espinel-Ingroff A, Fowler CL, Johnson EM, Knapp CC, Motyl MR, Ostrosky-Zeichner L, Sheehan DJ, Walsh TJ; Clinical and Laboratory Standards Institute Antifungal Testing Subcommittee. Wild-type MIC distribution and epidemiological cutoff values for Aspergillus fumigatus and three triazoles as determined by the Clinical and Laboratory Standards Institute broth microdilution methods. J Clin Microbiol. 2009; 47:3142-3146. http://dx.doi.org/10.1128/JCM.00940-09

24. Lass-Flörl C, Perkhofer S, Mayr A. In vitro susceptibility testing in fungi: a global perspective on a variety of methods. Mycoses. 2010; 53:1-11. http://dx.doi.org/10.1111/j.1439-0507.2009.01813.x

25. Lass-Flörl C. In vitro susceptibility testing in Aspergillus species: an update. Future Microbiol. 2010; 5:789-799. http://dx.doi.org/10.2217/fmb.10.34

26. Walsh TJ, Anaissie EJ, Denning DW, Herbrecht R, Kontoyiannis DP, Marr KA, Morrison VA, Segal BH, Steinbach WJ, Stevens DA, van Burik JA, Wingard JR, Patterson TF; Infectious Diseases Society of America. Treatment of aspergillosis: clinical practice guidelines of the Infectious Diseases Society of America. Clin Infect Dis. 2008; 46:327-360. http://dx.doi.org/10.1086/525258

27. Madureira A, Bergeron A, Lacroix C, Robin M, Rocha V, de Latour RP, Ferry C, Devergie A, Lapalu J, Gluckmana E, Socié G, Ghannoum M, Ribaud P. Breakthrough invasive aspergillosis in allogeneic haematopoietic stem cell transplant recipients treated with caspofungin. Int J Antimicrob Agents. 2007; 30:551-554. http://dx.doi.org/10.1016/j.ijantimicag.2007.07.026

28. Arendrup MC, Garcia-Effron G, Buzina W, Mortensen KL, Reite N, Lundin C, Jensen HE, Lass-Flörl C, Perlin DS, Bruun B. Breakthrough Aspergillus fumigatus and Candida albicans double infection during caspofungin treatment: laboratory characteristics and implication for susceptibility testing. Antimicrob Agents Chemother. 2009; 53:1185-1193. http://dx.doi.org/10.1128/AAC.01292-08

29. Pang KA, Godet C, Fekkar A, Scholler J, Nivoix Y, Letscher-Bru V, Massias L, Kauffmann-Lacroix C, Elsendoorn A, Uzunov M, Datry A, Herbrecht R. Breakthrough invasive mould infections in patients treated with caspofungin. J Infect. 2012; 64:424-429. http://dx.doi.org/10.1016/j.jinf.2011.12.015

30. Posteraro B, Torelli R, De Carolis E, Posteraro P, Sanguinetti M. Update on the laboratory diagnosis of invasive fungal infections. Mediterr J Hematol Infect Dis. 2011; 3:e2011002. http://dx.doi.org/10.4084/mjhid.2011.002

31. Pappas PG, Kauffman CA, Andes D, Benjamin DK Jr, Calandra TF, Edwards JE Jr, Filler SG, Fisher JF, Kullberg BJ, OstroskyZeichner L, Reboli AC, Rex JH, Walsh TJ, Sobel JD; Infectious Diseases Society of America. Clinical practice guidelines for the management of candidiasis: 2009 update by the Infectious Diseases Society of America. Clin Infect Dis. 2009; 48:503-535. http://dx.doi.org/10.1086/596757

32. Balajee SA, Houbraken J, Verweij PE, Hong SB, Yaghuchi T, Varga J, Samson RA. Aspergillus species identification in the clinical setting. Stud Mycol. 2007; 59:39-46. http://dx.doi.org/10.3114/sim.2007.59.05

33. Colozza C, Posteraro B, Santilli S, De Carolis E, Sanguinetti M, Girmenia C. In vitro activities of amphotericin B and AmBisome against Aspergillus isolates recovered from Italian patients treated for haematological malignancies. Int J Antimicrob Agents. 2012; 39:440-443. http://dx.doi.org/10.1016/j.ijantimicag.2012.01.013

34. Clinical and Laboratory Standards Institute. Reference method for broth dilution antifungal susceptibility testing of yeasts. Approved standard M27-A3, 3rd ed. Clinical and Laboratory Standards Institute. Wayne, PA. 2008.

35. Clinical and Laboratory Standards Institute. Reference method for broth dilution antifungal susceptibility testing of filamentous fungi. Approved standard M38-A2, 2nd ed. Clinical and Laboratory 
Standards Institute. Wayne, PA. 2008.

36. Subcommittee on Antifungal Susceptibility Testing of the ESCMID European Committee for Antimicrobial Susceptibility Testing. EUCAST definitive document EDef 7.1: method for the determination of broth dilution MICs of antifungal agents for fermentative yeasts. Clin Microbiol Infect. 2008; 14:398-405. http://dx.doi.org/10.1111/j.1469-0691.2007.01935.x

37. Arendrup MC, Cuenca-Estrella M, Lass-Flörl C, Hope W. EUCAST technical note on the EUCAST definitive document EDef 7.2: method for the determination of broth dilution minimum inhibitory concentrations of antifungal agents for yeasts EDef 7.2 (EUCAST-AFST). Clin Microbiol Infect. 2012; 18:E246-E247. http://dx.doi.org/10.1111/j.1469-0691.2012.03880.x

38. Subcommittee on Antifungal Susceptibility Testing of the ESCMID European Committee for Antimicrobial Susceptibility Testing. EUCAST Technical Note on the method for the determination of broth dilution minimum inhibitory concentrations of antifungal agents for conidia-forming moulds. Clin Microbiol Infect. 2008; 14:982-984. http://dx.doi.org/10.1111/j.14690691.2008.02086.x

39. Alastruey-Izquierdo A, Cuenca-Estrella M. EUCAST and CLSI: How to assess in vitro susceptibility and clinical resistance. Curr Fungal Infect Rep. 2012; 6:229-234. http://dx.doi.org/10.1007/s12281-012-0100-3

40. Cuenca-Estrella M, Rodriguez-Tudela JL. The current role of the reference procedures by CLSI and EUCAST in the detection of resistance to antifungal agents in vitro. Expert Rev Anti Infect Ther. 2010; 8:267-276. http://dx.doi.org/10.1586/eri.10.2

41. Rodríguez-Tudela JL, Arendrup MC, Cuenca-Estrella M, Donnelly JP, Lass-Flörl C. EUCAST breakpoints for antifungals. Drug News Perspect. 2010; 23:93-97. http://dx.doi.org/10.1358/dnp.2010.23.2.1400855

42. Cuenca-Estrella M. Antifungal drug resistance mechanisms in pathogenic fungi: from bench to bedside. Clin Microbiol Infect. 2013 Dec 21. [Epub ahead of print].

43. Perlin DS. Antifungal drug resistance: do molecular methods provide a way forward? Curr Opin Infect Dis. 2009; 22:568-573. http://dx.doi.org/10.1097/QCO.0b013e3283321ce5

44. Denning DW, Park S, Lass-Florl C, Fraczek MG, Kirwan M, Gore R, Smith J, Bueid A, Moore CB, Bowyer P, Perlin DS. Highfrequency triazole resistance found in nonculturable Aspergillus fumigatus from lungs of patients with chronic fungal disease. Clin Infect Dis. 2011; 52:1123-1129. http://dx.doi.org/10.1093/cid/cir179

45. Zhao Y, Stensvold CR, Perlin DS, Arendrup MC. Azole resistance in Aspergillus fumigatus from bronchoalveolar lavage fluid samples of patients with chronic diseases. J Antimicrob Chemother. 2013; 68:1497-1504. http://dx.doi.org/10.1093/jac/dkt071

46. Chai LY, Kullberg BJ, Johnson EM, Teerenstra S, Khin LW, Vonk AG, Maertens J, Lortholary O, Donnelly PJ, Schlamm HT, Troke PF, Netea MG, Herbrecht R. Early serum galactomannan trend as a predictor of outcome of invasive aspergillosis. J Clin Microbiol. 2012; 50:2330-2336. http://dx.doi.org/10.1128/JCM.06513-11

47. Soeffker G, Wichmann D, Loderstaedt U, Sobottka I, Deuse T, Kluge S. Aspergillus galactomannan antigen for diagnosis and treatment monitoring in cerebral aspergillosis. Prog Transplant.
2013; 23:71-74. http://dx.doi.org/10.7182/pit2013386

48. Pfaller MA, Chaturvedi V, Diekema DJ, Ghannoum MA, Holliday NM, Killian SB, Knapp CC, Messer SA, Miskou A, Ramani R. Comparison of the Sensititre YeastOne colorimetric antifungal panel with CLSI microdilution for antifungal susceptibility testing of the echinocandins against Candida spp., using new clinical breakpoints and epidemiological cutoff values. Diagn Microbiol Infect Dis. 2012; 73:365-368. http://dx.doi.org/10.1016/j.diagmicrobio.2012.05.008

49. Arendrup MC, Pfaller MA; Danish Fungaemia Study Group. Caspofungin Etest susceptibility testing of Candida species: risk of misclassification of susceptible isolates of C. glabrata and C. krusei when adopting the revised CLSI caspofungin breakpoints. Antimicrob Agents Chemother. 2012; 56:3965-3968. http://dx.doi.org/10.1128/AAC.00355-12

50. Astvad KM, Perlin DS, Johansen HK, Jensen RH, Arendrup MC Evaluation of caspofungin susceptibility testing by the new Vitek 2 AST-YS06 yeast card using a unique collection of FKS wild-type and hot spot mutant isolates, including the five most common Candida species. Antimicrob Agents Chemother. 2013; 57:177182. http://dx.doi.org/10.1128/AAC.01382-12

51. Cuenca-Estrella M, Verweij PE, Arendrup MC, Arikan-Akdagli S, Bille J, Donnelly JP, Jensen HE, Lass-Flörl C, Richardson MD, Akova M, Bassetti M, Calandra T, Castagnola E, Cornely OA, Garbino J, Groll AH, Herbrecht R, Hope WW, Kullberg BJ, Lortholary O, Meersseman W, Petrikkos G, Roilides E, Viscoli C, Ullmann AJ; ESCMID Fungal Infection Study Group. ESCMID* guideline for the diagnosis and management of Candida diseases 2012: diagnostic procedures. Clin Microbiol Infect. 2012; 18 Suppl 7:9-18. http://dx.doi.org/10.1111/1469-0691.12038

52. van der Linden JW, Camps SM, Kampinga GA, Arends JP, Debets-Ossenkopp YJ, Haas PJ, Rijnders BJ, Kuijper EJ, van Tiel FH, Varga J, Karawajczyk A, Zoll J, Melchers WJ, Verweij PE. Aspergillosis due to voriconazole highly resistant Aspergillus fumigatus and recovery of genetically related resistant isolates from domiciles. Clin Infect Dis. 2013; 57:513-520. http://dx.doi.org/10.1093/cid/cit320

53. Vale-Silva LA, Buchta V. Antifungal susceptibility testing by flow cytometry: is it the future? Mycoses. 2006; 49:261-273. http://dx.doi.org/10.1111/j.1439-0507.2006.01243.x

54. Vale-Silva LA, Pinto P, Lopes V, Ramos H, Pinto E. Comparison of the Etest and a rapid flow cytometry-based method with the reference CLSI broth microdilution protocol M27-A3 for the echinocandin susceptibility testing of Candida spp. Eur J Clin Microbiol Infect Dis. 2012; 31:941-946. http://dx.doi.org/10.1007/s10096-011-1390-z

55. Vella A, De Carolis E, Vaccaro L, Posteraro P, Perlin DS, Kostrzewa M, Posteraro B, Sanguinetti M. Rapid antifungal susceptibility testing by matrix-assisted laser desorption ionizationtime of flight mass spectrometry analysis. J Clin Microbiol. 2013; 51:2964-2969. http://dx.doi.org/10.1128/JCM.00903-13

56. Furustrand Tafin U, Clauss M, Hauser PM, Bille J, Meis JF, Trampuz A. Isothermal microcalorimetry: a novel method for realtime determination of antifungal susceptibility of Aspergillus species. Clin Microbiol Infect. 2012; 18:E241-E245. http://dx.doi.org/10.1111/j.1469-0691.2012.03854.x 